\title{
A novel strategy of EGFR-TKI combined chemotherapy in the treatment of human lung cancer with EGFR-sensitive mutation
}

\author{
LANLIN ZHANG $^{1,2}$, YUAN QI ${ }^{1,2}$, KAILIN XING $^{1,2},{\text { SONG } \text { QIAN }^{1,2}, \text { PING ZHANG }^{3} \text { and XIANGHUA WU }}^{1,2}$ \\ ${ }^{1}$ Department of Medical Oncology, Fudan University Shanghai Cancer Center; ${ }^{2}$ Department of \\ Oncology, Shanghai Medical College, Fudan University; ${ }^{3}$ Cancer Research Institute of \\ Fudan University Shanghai Cancer Center, Shanghai 200032, P.R. China
}

Received February 1, 2018; Accepted June 13, 2018

DOI: 10.3892/or.2018.6499

\begin{abstract}
The discovery of epidermal growth factor receptor (EGFR)-sensitive mutations in non-small cell lung cancer (NSCLC) and the successful clinical application of EGFR tyrosine kinase inhibitors (TKIs) have changed the regimen of lung cancer therapy from traditional cytotoxic chemotherapy to molecular-targeted cancer therapy. However, the main limitation of EGFR-TKI therapy is the heterogeneity of lung cancer harboring EGFR-sensitive mutations. In addition, the synergistic effect of the administration of chemotherapy and EGFR-TKIs, combined with tumor heterogeneity, on NSCLC remains unclear. The present study aimed to investigate the optimal schedule for combined treatment with paclitaxel/gemcitabine and gefitinib in co-cultured NSCLC cell lines, in which PC9 cells were mixed with A549 cells at $0: 1,1: 19,1: 3,1: 1,3: 1$ and 1:0 ratios, and clarified the associated mechanisms. The mixed cells were used to simulate the tumor heterogeneity in the human cancer environment and to define the differential anti-proliferative effects of nine schedules of paclitaxel/gemcitabine and gefitinib, based on cell cycle distribution. We confirmed that gefitinib arrested PC9 cell growth, mainly at the G1 phase, at $24 \mathrm{~h}$ regardless of low or high concentration. After a 24-h culture in gefitinib-free medium, the cell cycle returned to its normal state. Paclitaxel and gemcitabine induced G2/M phase and $S$ phase arrest at $72 \mathrm{~h}$, respectively. The anti-proliferative effect of paclitaxel/gemcitabine followed by gefitinib resulted in the optimum anti-proliferative activity compared with the other seven schedules, which was not affected by tumor heterogeneity. Cell cycle-dependent synergism may contribute to this effect. Our results are in accordance with most of the existing clinical trials, and could provide a potential treatment
\end{abstract}

Correspondence to: Dr Xianghua Wu, Department of Medical Oncology, Fudan University Shanghai Cancer Center, 270 Dong-An Road, Shanghai 200032, P.R. China

E-mail: wuxianghua2018@163.com

Key words: epidermal growth factor receptor, tyrosine kinase inhibitor, chemotherapy, heterogeneity, cell cycle, lung cancer option for patients with advanced NSCLC and for the ongoing clinical investigation of the sequential treatment of NSCLC.

\section{Introduction}

Lung cancer, of which approximately $85 \%$ is non-small cell lung cancer (NSCLC), is one of the leading causes of cancer mortality worldwide (1). Being superior to traditional chemotherapy, epidermal growth factor receptor (EGFR)-tyrosine kinase inhibitors (TKIs) have become a standard first-line treatment for advanced NSCLC with EGFR-sensitive mutation (2). Recently, two phase III studies have found that tumors with EGFR-sensitive mutations are highly sensitive to EGFR-TKIs, with a better prognosis compared to carboplatin plus paclitaxel or pemetrexed plus carboplatin chemotherapy regimens $(3,4)$. However, EGFR-TKIs achieve a complete response in less than $5 \%$ of patients and have reached a therapeutic plateau, with a median progression-free survival (PFS) no longer than 13 months (5).

Since gefitinib treatment for patients with EGFR-sensitive mutations does not last long, considering that patients inevitably and ultimately develop T790M resistance $(6,7)$, some novel treatment modalities against NSCLC, involving the integration of EGFR-TKIs with cytotoxic chemotherapy, have been designed to conquer these problems. A randomized phase II study demonstrated the superiority of EGFR-TKIs combined with pemetrexed compared with gefitinib alone in prolonging PFS and increasing the objective response rate (ORR) in advanced NSCLC patients harboring EGFR-sensitive mutations (8). Other studies found that intercalating gefitinib into chemotherapy compared to chemotherapy alone could prolong PFS and overall survival (OS) (9-11). Nevertheless, a meta-analysis of nine randomized trials showed that there was no benefit to OS associated with first-line TKI followed by second-line platinum-based doublet chemotherapy compared to the reverse sequence in NSCLC patients with EGFR mutation (12). Although there are many previous studies into the sequence-dependent interactions between EGFR-TKIs and chemotherapy in human cancer cell lines with EGFR mutation, optimal therapeutic regimens remain unclear. Therefore, we aimed to understand the principle of synergistic or antagonistic effects between different EGFR-TKI and chemotherapy sequence regimens in combination with cell cycle distribution. 
Gemcitabine and paclitaxel are active agents in the treatment of a variety of human malignancies, particularly NSCLC (13). Gemcitabine arrests the cell cycle at the $\mathrm{S}$ phase (14), while paclitaxel causes $\mathrm{M}$ phase cell accumulation (15). Understanding cell cycle disturbances caused by the two drugs may aid in the design of the most appropriate treatment schedule.

In the present study, human lung cancer cells with different EGFR mutations, co-cultured in order to simulate the tumor heterogeneity of human NSCLC, were used to investigate the differential anti-proliferative effects of gemcitabine, paclitaxel and gefitinib in different schedules based on the cell cycle distribution. Specifically, we tested the anti-proliferative effects of gemcitabine/paclitaxel and gefitinib in nine different schedules.

\section{Materials and methods}

Drugs and chemicals. Gefitinib, purchased from Selleck Chemicals (Houston, TX, USA), was dissolved in dimethyl sulfoxide (DMSO; Sigma-Aldrich; Merck KGaA, Darmstadt, Germany) to a 1-mM stock solution. Paclitaxel was purchased from Sigma-Aldrich (Merck KGaA) and was dissolved in phosphate-buffered saline (PBS) to a 7-mM stock solution. Gemcitabine was purchased from Sigma-Aldrich (Merck KGaA) and was dissolved in PBS at $100 \mathrm{mM}$ as the stock solution. The drugs were stored at $-20^{\circ} \mathrm{C}$ and diluted with culture medium prior to use.

Cell lines. The human NSCLC A549 cell line without the EGFR 19 exon mutation and the PC9 cell line with the EGFR 19 exon mutation were purchased from the American Type Culture Collection (ATCC, Manassas, VA, USA) and maintained in RPMI-1640 medium (GE Healthcare-Hyclone Laboratories, Logan, UT, USA), supplemented with $10 \%$ fetal bovine serum (FBS; Biological Industries, Beith Haemek, Israel), penicillin $(100 \mathrm{U} / \mathrm{ml})$ and streptomycin $(100 \mu \mathrm{g} / \mathrm{ml})$ at $37^{\circ} \mathrm{C}$ in $5 \% \mathrm{CO}_{2}$. The cells were then harvested with trypsin-EDTA when they had reached the point of exponential growth.

DNA extraction. Genomic DNA was extracted from the A549 and PC9 lung cancer cells using a TIANamp blood DNA extraction kit (Tiangen Biotech, Beijing, China), according to the manufacturer's instructions. The A260 and A280 of the DNA samples were tested to measure the quantity and purity of the genomic DNA. All DNA samples were dissolved in distilled water and stored at $-20^{\circ} \mathrm{C}$.

PCR and sequencing of the EGFR 19 exon gene. Exon 19 encoding the intracellular domain of EGFR was amplified from genomic DNA and directly sequenced. The pair of primers targeting exon 19 of the EGFR gene was designed using Primer Premier 5.0 (Premier Biosoft International, Palo Alto, CA, USA). The sequences were as follows: Exon 19 forward, 5'-AGCCCCCAGCAATATCAGCCTTAGGTG-3' and reverse, 5'-CTTAGAGACAGCACTGGCCTCTCCC AT-3'. PCR amplification was carried out on a PTC-200 DNA thermocycler (MJ Research, Inc., Boston, MA, USA) in a 25- $\mu$ l reaction system containing $20 \mathrm{ng}$ template DNA, $1 \mathrm{X}$ PCR buffer for KOD-Plus-Neo, $1.5 \mathrm{mM} \mathrm{Mg}_{2} \mathrm{SO}_{4}, 0.2 \mathrm{mM}$ of each
dNTP, $0.3 \mu \mathrm{M}$ of each primer and 0.5 units KOD-Plus-Neo DNA polymerase (Toyobo, Co., Ltd., Osaka, Japan). The PCR cycling conditions consisted of an initial denaturation step at $94^{\circ} \mathrm{C}$ for $2 \mathrm{~min}$, followed by 40 cycles of denaturation at $98^{\circ} \mathrm{C}$ for $10 \mathrm{sec}$, annealing at $63.5^{\circ} \mathrm{C}$ for $30 \mathrm{sec}$ and extension at $68^{\circ} \mathrm{C}$ for $30 \mathrm{sec}$. PCR products were purified and sent to Shanghai Biosune Biotech Co., Ltd., (Shanghai, China) for sequencing.

Flow cytometric analysis of cell cycle distribution. PC9 cells were seeded into 6 -well plates at a density of $3 \times 10^{5} /$ well. After the cells became adherent in complete medium overnight, they were incubated with serum-free medium for $24 \mathrm{~h}$, and treated with gefitinib at $0,0.5 \mathrm{x} \mathrm{IC}_{50}, \mathrm{IC}_{50}$ and $2 \mathrm{x} \mathrm{IC} \mathrm{I}_{50}$ levels in medium with $10 \%$ FBS for $24 \mathrm{~h}$. After PC9 cells were treated with gefitinib at the $\mathrm{IC}_{50}$ level for $24 \mathrm{~h}$, cells were cultured in gefitinib-free medium for $24 \mathrm{~h}$. In addition, the PC9 cells were exposed to paclitaxel and gemcitabine as single agents at the concentration of their respective $\mathrm{IC}_{50}$ levels for $72 \mathrm{~h}$. After the start of these treatments, adherent cells were trypsinized, counted, washed and resuspended, along with the corresponding floating cells. The cells were then washed and fixed via dropwise addition of $75 \%$ ice-cold ethanol, and stored in PBS overnight at $-20^{\circ} \mathrm{C}$. After fixation, cells were washed three times with cold PBS and then stained in $500 \mu \mathrm{l}$; propidium iodide (PI)-RNase staining buffer solution (BD Biosciences, San Jose, CA, USA) for $15 \mathrm{~min}$ at room temperature. Samples were analyzed on a flow cytometer (BD Biosciences, San Jose, CA, USA) and the percentage of cells in the S, G1 and G2-M phases of the cell cycle was determined. The assay was carried out in triplicate and repeated three times.

Treatment regimens. Cell viability was determined by Cell Counting Kit-8 (CCK-8) assays using a CCK-8 (Dojindo Laboratories, Kumamoto, Japan) and performed according to the manufacturer's protocol. Briefly, cells were seeded in 96-well plates $\left(4 \times 10^{3} /\right.$ well), and PC9 cells were mixed with A549 cells at 0:1, 1:19, 1:3, 1:1, 3:1 and 1:0 ratios. After $12 \mathrm{~h}$, paclitaxel, gemcitabine and gefitinib were added based on the obtained $\mathrm{IC}_{50}$ values according to different sequences. A total of $10 \%$ CCK-8 solution was added to each well at $72 \mathrm{~h}$, and the plates were incubated at $37^{\circ} \mathrm{C}$ in $5 \% \mathrm{CO}_{2}$ for $2 \mathrm{~h}$. The absorbance of each sample was measured at a wavelength of $450 \mathrm{~nm}$ using a microplate reader. In order to evaluate the anti-proliferative effects of combined treatment, nine different sequences were designed: i) Pretreated with gefitinib for $48 \mathrm{~h}$, aspirated and washed once with PBS and re-dosed every $24 \mathrm{~h}$, followed by paclitaxel for $24 \mathrm{~h}$; ii) Pretreated with paclitaxel for $24 \mathrm{~h}$, aspirated and washed once with PBS, followed by gefitinib for $48 \mathrm{~h}$, and cells were aspirated and washed once with PBS and re-dosed every $24 \mathrm{~h}$; iii) Pretreated with a double gefitinib dose for $24 \mathrm{~h}$, aspirated and washed once with PBS, followed by drug-free medium for $24 \mathrm{~h}$ intervals, and then aspirated and washed again, followed by paclitaxel for $24 \mathrm{~h}$; iv) Pretreated with gefitinib for $72 \mathrm{~h}$, and cells were aspirated and washed once with PBS and re-dosed every $24 \mathrm{~h}$; v) Pretreated with paclitaxel for $72 \mathrm{~h}$, and cells were aspirated and washed once with PBS and re-dosed every $24 \mathrm{~h}$; vi) Pretreated with gefitinib for $48 \mathrm{~h}$, aspirated and washed once with PBS and re-dosed every $24 \mathrm{~h}$, followed by gemcitabine for $24 \mathrm{~h}$; vii) Pretreated with gemcitabine for 
$24 \mathrm{~h}$, aspirated and washed once with PBS, followed by gefitinib for $48 \mathrm{~h}$, and cells were aspirated and washed once with PBS and re-dosed every $24 \mathrm{~h}$; viii) Pretreated with a double gefitinib dose for $24 \mathrm{~h}$, aspirated and washed once with PBS, followed by drug-free medium for 24-h intervals, and then aspirated and washed again, followed by gemcitabine for $24 \mathrm{~h}$; and ix) Pretreated with gemcitabine for $72 \mathrm{~h}$, and cells were aspirated and washed once with PBS and re-dosed every $24 \mathrm{~h}$. The assay was carried out in triplicate and the results of more than three independent experiments are presented.

Cell proliferation and viability. Vi-Cell XR (Beckman Coulter, Inc., Brea, CA, USA), an automated cell viability analyzer based on dead cell exclusion analysis, was used to measure the numbers of cells. PC9 cells were mixed with A549 cells at 0:1, 1:1 and 1:0 ratios. Cells $\left(10^{4}\right)$ were placed in 24-well culture plates in standard culture medium with $10 \%$ FBS. At days 1, 2, 3, 4, 5, 6 and 7, cells were trypsinized and quantified using Vi-Cell XR. Experiments were repeated three times to ensure the accuracy of the results. Three replicate experiments were performed for each analysis, and the mean for each experiment was calculated. The assay was performed in triplicate and repeated three times.

Statistical analysis. The results obtained from at least three independent experiments are presented as the mean \pm standard error (SE) of at least three experiments. Statistical comparisons of sequence-dependent effects were conducted using Student's $t$ tests and analysis of variance. Statistics and graphs were generated using GraphPad Prism software (ver.6.00 for Mac; GraphPad Prism Software, Inc., La Jolla, CA, USA). P<0.05 was considered to indicate a statistically significant difference.

\section{Results}

Sequencing of the EGFR 19 exon gene. Specific primers were used for amplifying the cDNA fragments of the EGFR tyrosine kinase domain. Among the sequences from the A549 cell line and the PC9 cell line, we found that 15-bp were deleted in the PC9 cell line, and the A549 cell was wild-type for EGFR (Fig. 1).

Cell cycle modulation by gefitinib. DNA flow cytometer studies were performed to evaluate the effect of single gefitinib treatment on cell cycle distribution and to determine whether different gefitinib exposure doses would modulate the cell cycle, which may provide clues for optimizing the drug sequence. Gefitinib caused a G1 arrest within $24 \mathrm{~h}$ at $0.5 \mathrm{x} \mathrm{IC}$, $\mathrm{IC}_{50}$ and $2 \mathrm{x} \mathrm{IC}_{50}$ concentrations (Fig. 2A). After treatment for $24 \mathrm{~h}$ with gefitinib, followed by a 24 -h interval with drug-free medium, the PC9 cells were returned to the normal cell cycle distribution compared with the control group (Fig. 2B). These results indicated that gefitinib could induce $\mathrm{G} 1$ phase cell cycle arrest after $24 \mathrm{~h}$, and that the cells could return to their normal state after $24 \mathrm{~h}$ with drug-free medium. In addition, gemcitabine and paclitaxel arrested PC9 cells at the $\mathrm{G} 2 / \mathrm{M}$ and $\mathrm{S}$ phase at $72 \mathrm{~h}$, respectively (Fig. 2C and D).

A sequence of paclitaxel/gemcitabine followed by gefitinib is the most effective regimen compared with the other seven
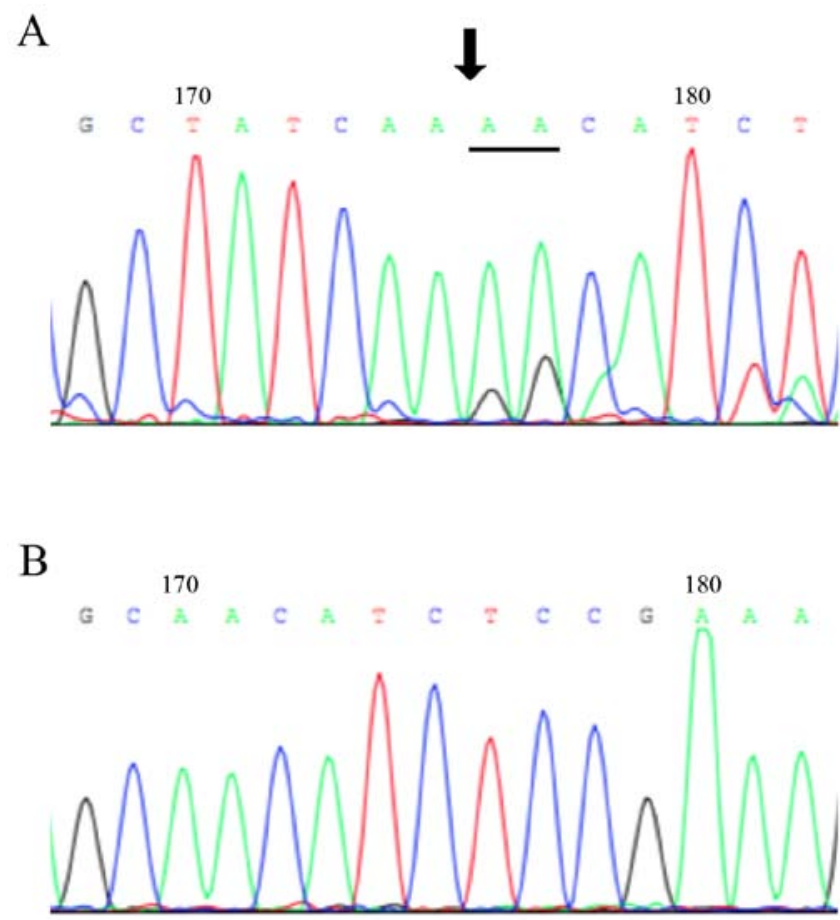

Figure 1. EGFR exon 19 was sequenced in PC9 and A549 cells. (A) PC9 cells exhibited 15-bp deletions in the EGFR exon 19 sequences. (B) A549 cells exhibited EGFR exon 19 wild-type sequences.

sequences in the different mixed populations of NSCLC cell lines. To evaluate the anti-proliferative effects of paclitaxel/gemcitabine and gefitinib treatment, we performed a series of CCK-8 cell growth assays. PC9 cells were highly sensitive to gefitinib, while A549 cells exhibited primary resistance to gefitinib. All of these cell lines demonstrated similar sensitivities to paclitaxel and gemcitabine. We evaluated the anti-proliferative effects on the six mixed populations of A549 and PC9 cell lines in nine sequences.

Gemcitabine and paclitaxel exerted an antitumor effect in the A549 and PC9 cell lines when used as single agents. Subsequent to a 72-h exposure, the $\mathrm{IC}_{50}$ values of gemcitabine and paclitaxel in the A549 cells were $0.8164 \mu \mathrm{M}$ and $0.1437 \mu \mathrm{M}$ and the $\mathrm{IC}_{50}$ values of gemcitabine and paclitaxel in the PC9 cells were, $0.2463 \mu \mathrm{M}$ and $16.86 \mathrm{nM}$, respectively (Table I). Additionally, the $\mathrm{IC}_{50}$ value of gefitinib in the PC9 cells was $15 \mathrm{nM}$.

We then evaluated the anti-proliferative effects of different sequence-dependent regimens of paclitaxel/gemcitabine and gefitinib on co-cultured human lung cancer cell lines. The schedules for in vitro sequences of treatment with paclitaxel/gemcitabine and gefitinib are presented (Figs. 3A and 4A). Sequential administrations of paclitaxel/gemcitabine followed by gefitinib (group b/g), and a double gefitinib dose followed by paclitaxel/gemcitabine (group c/h) both induced a clear synergistic effect. On the contrary, only the gefitinib followed by paclitaxel/gemcitabine (group a/f) resulted in an antagonistic interaction. Although group $\mathrm{b} / \mathrm{g}$ and group $\mathrm{c} / \mathrm{h}$ resulted in a significant anti-proliferative effect, the inhibition rate of group $b$ was prior to the group $c$; the inhibition rate of group $g$ was better than that of group $\mathrm{h}$. In addition, we also compared a paclitaxel/gemcitabine-gefitinib combination (group b/g) 
A

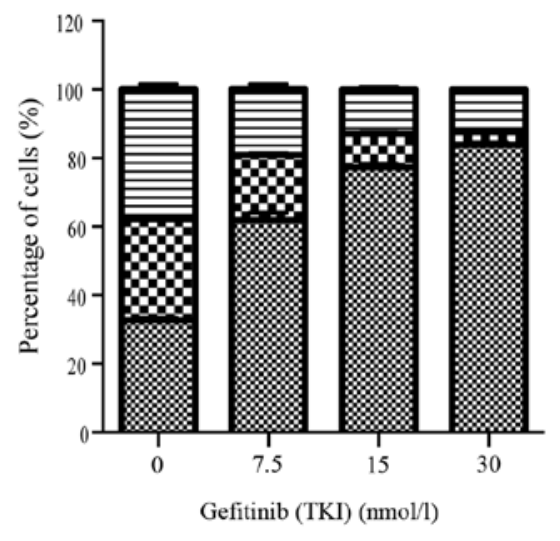

$\mathrm{C}$

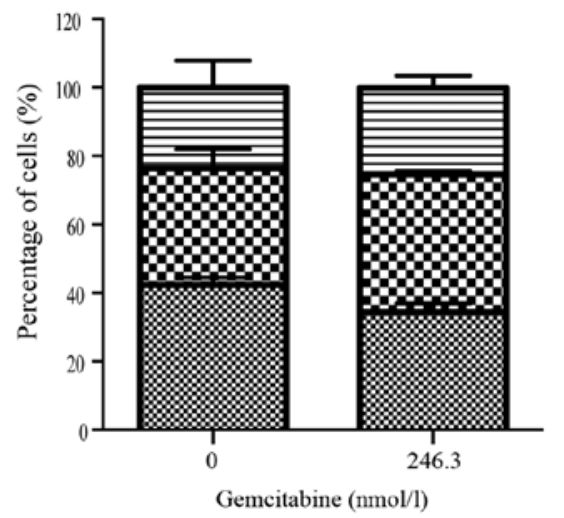

B

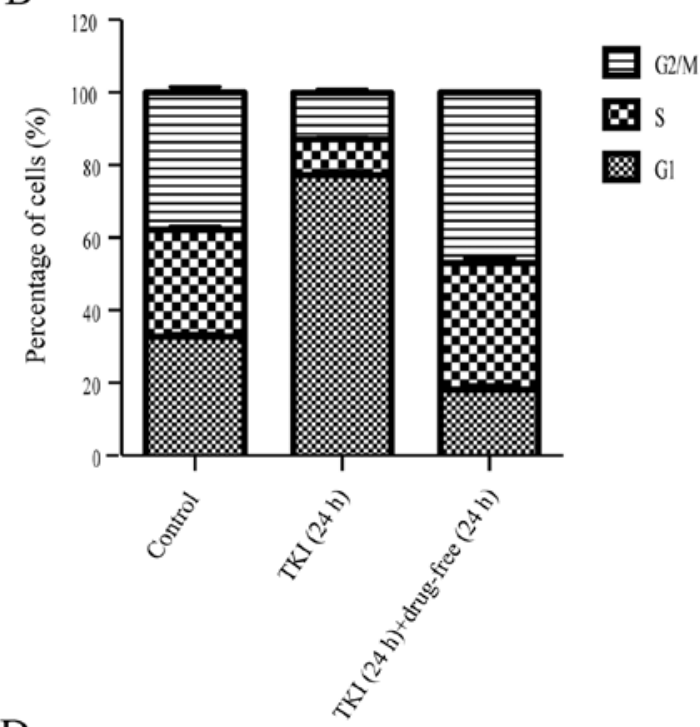

$\mathrm{D}$

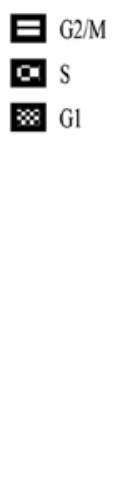

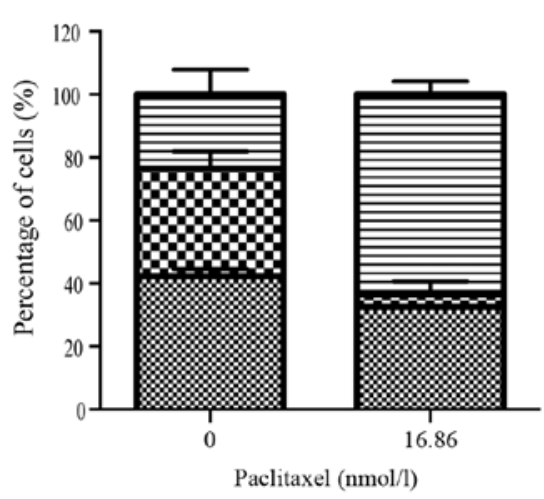

Figure 2. Gefitinib mainly induced G1 arrest in PC9 cells. After treatment for $24 \mathrm{~h}$ with gefitinib, followed by a 24-h interval with drug-free medium, the PC9 cells were returned to the normal cell cycle distribution. Paclitaxel and gemcitabine induced G2/M phase and S phase arrest at $72 \mathrm{~h}$, respectively. (A) PC9 cells were treated with $0,7.5,15$ and $30 \mathrm{nmol} / 1$ gefitinib for $24 \mathrm{~h}$. (B) PC9 cells were treated with $15 \mathrm{nmol} / 1$ gefitinib for $24 \mathrm{~h}$ and cultured in drug-free conditions for $24 \mathrm{~h}$. (C) PC9 cells were treated with 0 and $246.3 \mathrm{nmol} / 1$ gemcitabine for $72 \mathrm{~h}$. (D) PC9 cells were treated with 0 and $16.86 \mathrm{nmol} / 1$ paclitaxel for $72 \mathrm{~h}$. Columns in the diagram depict the cell cycle phase distribution of PC9 cells.

Table I. $\mathrm{IC}_{50}$ values.

\begin{tabular}{lcc}
\hline \multirow{2}{*}{ Agent } & \multicolumn{2}{c}{$\mathrm{IC}_{50 \text { values }}$ for cell line } \\
\cline { 2 - 3 } & $\mathrm{A} 549$ & PC9 \\
\hline Paclitaxel & $0.1437 \mu \mathrm{M}$ & $16.86 \mathrm{nM}$ \\
Gemcitabine & $0.8614 \mu \mathrm{M}$ & $0.2463 \mu \mathrm{M}$ \\
\hline
\end{tabular}

$\mathrm{IC}_{50}$ values for each agent were calculated by performing dose response experiments with paclitaxel and gemcitabine. Each test was performed in triplicate.

with paclitaxel/gemcitabine alone (group e/i) or gefitinib alone (group d); the treatment in group b/g was more efficacious than the single-agent regimens. Hence, these results confirmed the superiority of the group $b$ and group $g$ regimens among the nine different schedules. The two groups exhibited significantly diminished cell viability in the mixed populations of NSCLC cells, which indicated a synergistic effect $(\mathrm{P}<0.05)$. The combined effect of paclitaxel/gemcitabine and gefitinib was evaluated on the basis of the P-value (Figs. 3B and 4B). In addition, the anti-proliferative effects were not changed by the six different co-culturing ratios. The anti-proliferative effects of paclitaxel and gemcitabine in the different sequences were similar.

Cell proliferation and viability assays. To elucidate the underlying growth interactions of A549 and PC9 cells, we conducted cell proliferation and viability assays. PC9 cells were grown in groups, which was different from A549 cells (Fig. 5A and B). Comparing the co-cultured cells, there was no significant synergistic or inhibitory effect between them, as observed by microscopy (Fig. 5C and D). After 7 days, the cell proliferation of A549 and PC9 cells at 0:1, 1:1 and 1:0 ratios was assessed (Fig. 5E). There was no relevant effect between the co-cultured A549 and PC9 cells. Additionally, the growth curves were completely coincident at 3 days, and the 7-day growth curves failed to reach statistical significance $(\mathrm{P}=0.6373)$. 
A

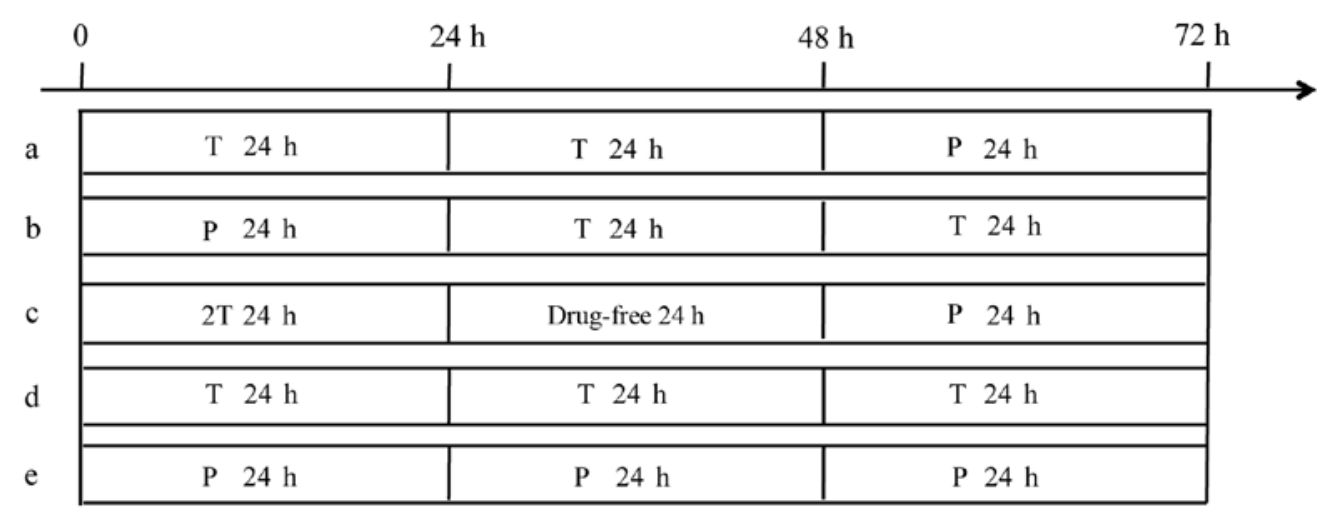

B
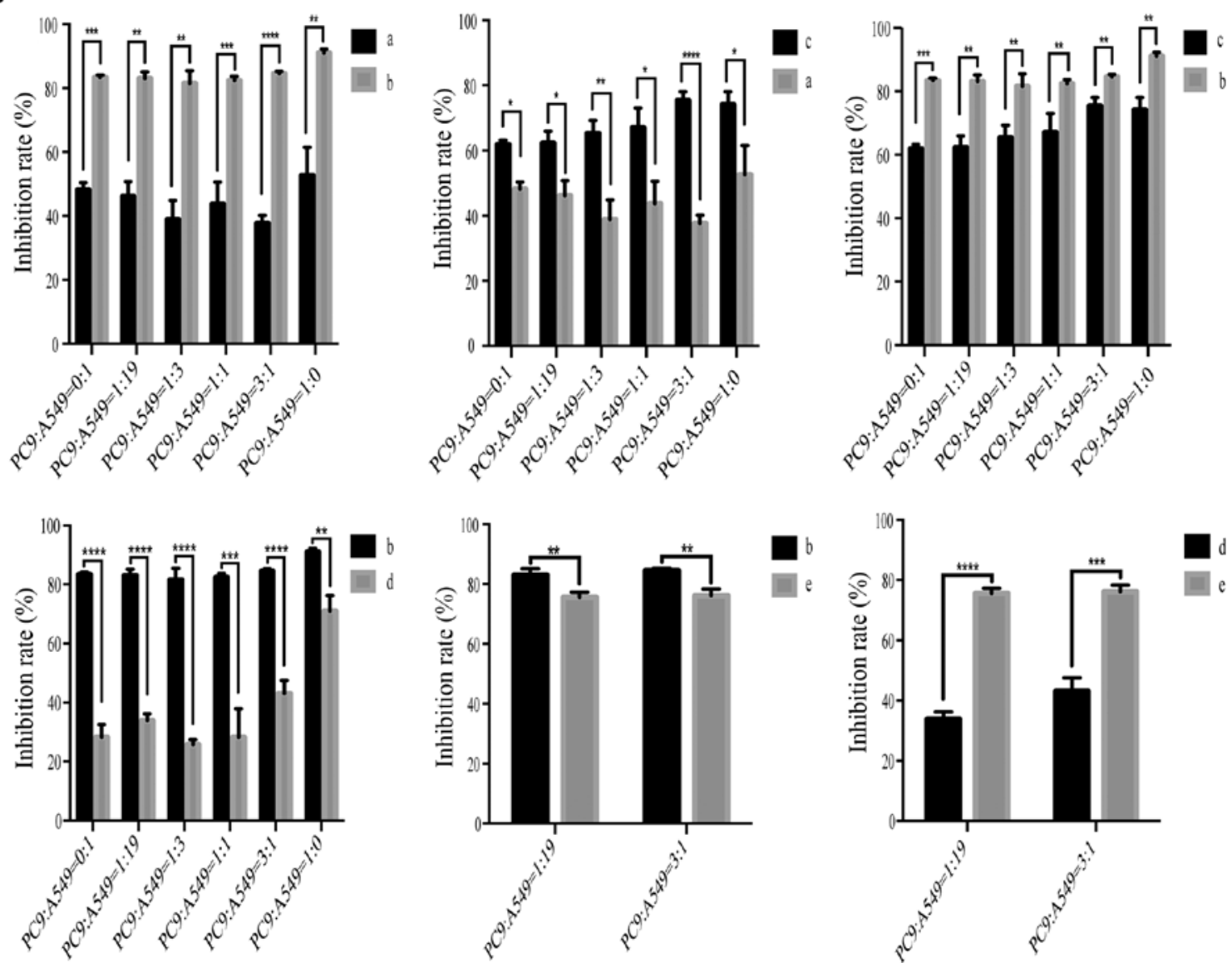

Figure 3. The anti-proliferative effects of paclitaxel combined with gefitinib are sequence-dependent. (A) Schedules of sequential treatment: a) gefitinib followed by paclitaxel; b) paclitaxel followed by gefitinib; c) double dosage of gefitinib followed by paclitaxel; d) gefitinib alone for $72 \mathrm{~h}$; e) paclitaxel alone for $72 \mathrm{~h}$. T, gefitinib; P, paclitaxel. (B) The sequence of paclitaxel followed by gefitinib produced the most potent anti-proliferative effect in the NSCLC cell lines. The inhibition rate was determined by CCK-8 assay. ${ }^{*} \mathrm{P}<0.0198,{ }^{* * *} \mathrm{P}<0.01,{ }^{* * *} \mathrm{P}<0.0003,{ }^{* * * * *} \mathrm{P}<0.0001$.

\section{Discussion}

In the present study, the flow cytometric analysis revealed that gefitinib stagnated PC9 cells at the G1 phase regardless of the concentration or exposure time, and paclitaxel and gemcitabine induced G2/M phase and S phase arrest at $72 \mathrm{~h}$, respectively. We also demonstrated that the sequence of gemcitabine/paclitaxel followed by gefitinib resulted in an optimum significantly synergistic effect on the NSCLC co-cultured cell lines among the nine different schedules. In addition, this anti-proliferative effect seemed to have no correlation with the different constitutive expression levels of the EGFR mutation.

In accordance with these sequence-dependent results, the FASTACT-1 and FASTACT-2 trials revealed that intercalating erlotinib into chemotherapy could lead to an improvement in terms of prolonging PFS and OS $(16,17)$. The NCT02148380 and UMIN000003808 trials found that treatment with pemetrexed plus carboplatin combined with gefitinib could provide better survival benefits for patients with lung adenocarcinoma harboring EGFR-sensitive mutations $(18,19)$. Furthermore, 
A

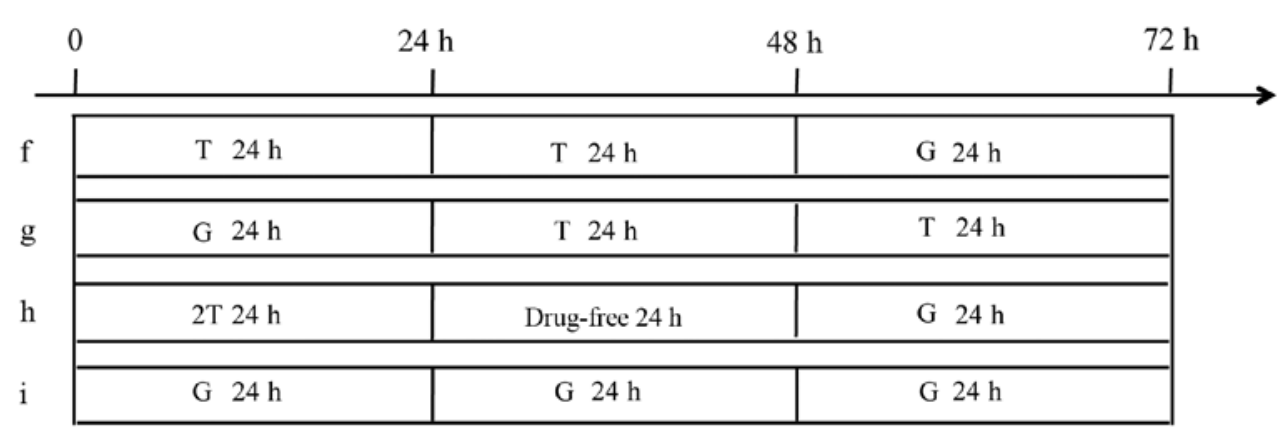

B
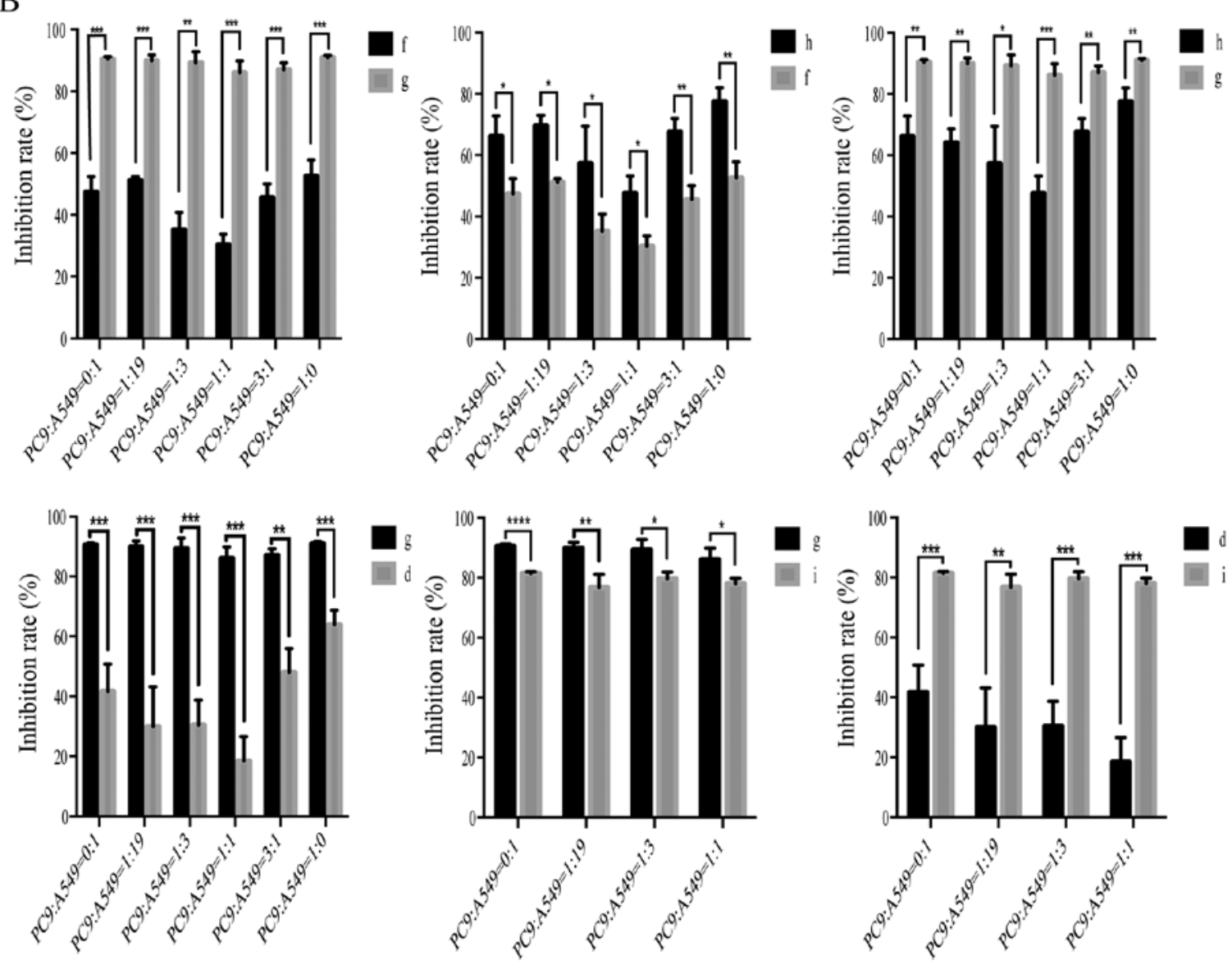

Figure 4. The anti-proliferative effects of gemcitabine combined with gefitinib are sequence-dependent. (A) Schedules of sequential treatment: f) gefitinib followed by gemcitabine; g) gemcitabine followed by gefitinib; h) two doses of gefitinib followed by gemcitabine; i) gemcitabine alone for $72 \mathrm{~h}$. T, gefitinib; G, gemcitabine. (B) The sequence of gemcitabine followed by gefitinib produced the most potent anti-proliferative effect in the NSCLC cell lines. The inhibition rate was determined by CCK- 8 assay. ${ }^{*} \mathrm{P}<0.0198,{ }^{* *} \mathrm{P}<0.01,{ }^{* * *} \mathrm{P}<0.0003,{ }^{* * * * *} \mathrm{P}<0.0001$.

other phase II and III clinical trials observed that first-line erlotinib/gefitinib followed by chemotherapy was significantly inferior in terms of OS compared with the sequence of first-line chemotherapy followed by erlotinib/gefitinib $(20,21)$, which once again confirmed the reliability of our experimental results. Obviously, using a strategy comprising of a sequence of EGFR-TKIs with chemotherapy, we demonstrated that, compared to single target therapy, the sequential therapy significantly prolonged PFS and OS; however, we need a better understanding of the principle underlying the different schedules in order to choose the optimal treatment regimen.

Given that the phase II and III clinical trials were unsuccessful, the failure to achieve sensitive results may be due to the inability to adopt appropriate drug administration sequences. In fact, the G1 cell cycle arrest caused by EFGR-TKIs may reduce the cell cycle phase-dependent activity of chemotherapy, thereby leading to cell cycle-specific antagonism $(22,23)$. In brief, the sequence of gefitinib followed by paclitaxel/gemcitabine resulted in an antagonistic interaction. As gefitinib was administered before paclitaxel/gemcitabine, gefitinib caused the tumor cells to undergo G1 phase arrest, which prevented the cytotoxic effects of subsequently administered paclitaxel/gemcitabine. By contrast, the sequence of paclitaxel/gemcitabine followed by gefitinib could be sufficient to allow for chemotherapy-induced $\mathrm{S}$ phase and G2/M phase arrest to improve the targeted effects of the subsequent 
A

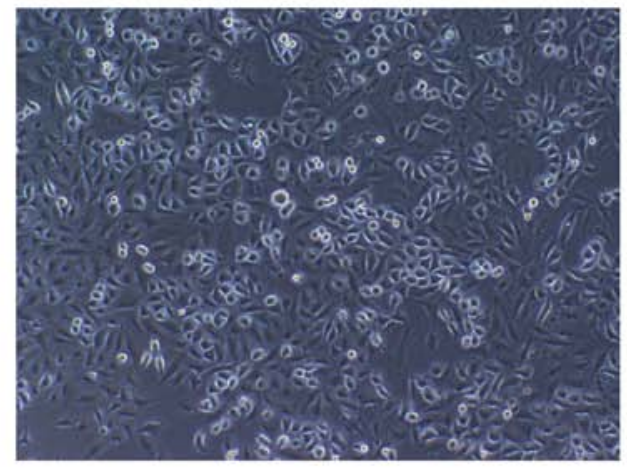

PC9

C

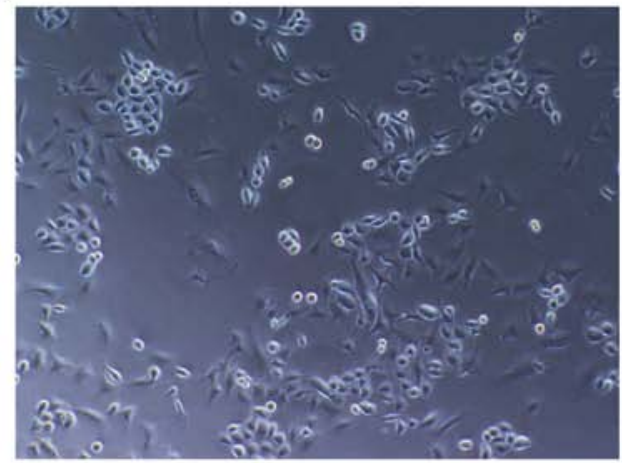

A549+PC9

\section{E}

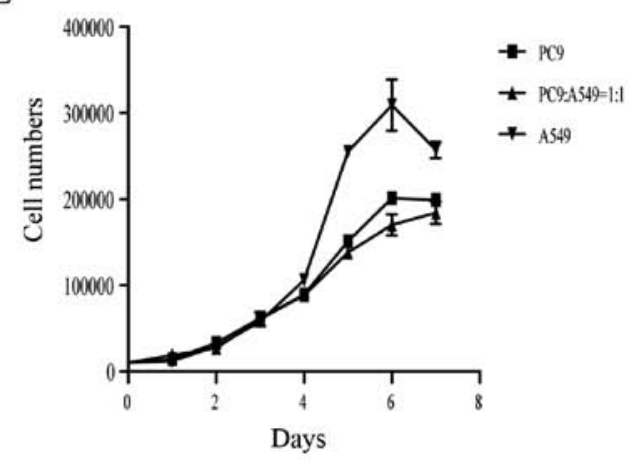

B

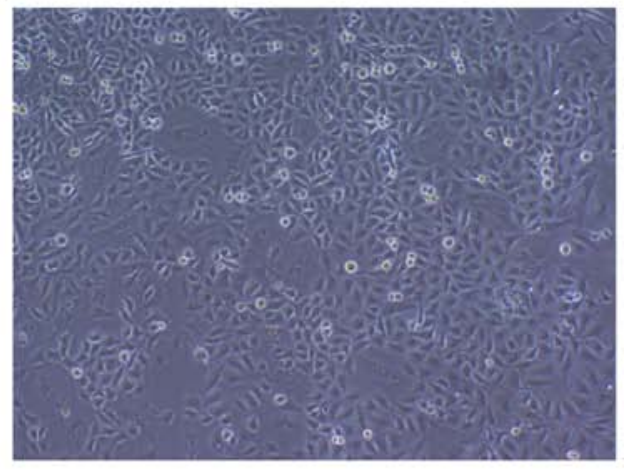

A549

D

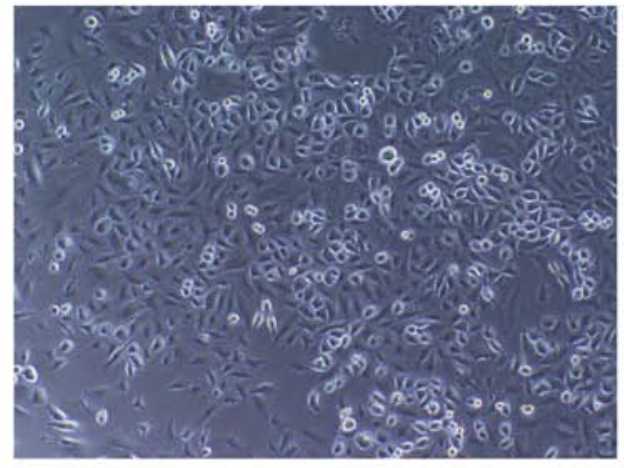

A549+PC9

Figure 5. A549 and PC9 cells were co-cultured without drugs, and cell counts and cell viability were determined using Vi-Cell XR. The representation of viable cells was determined and counted using Vi-Cell XR every day for 7 days. (A) Image showing the growth of PC9 cells. (B) Image showing the growth of A549 cells. (C and D) Co-culture of A549 cells mixed with PC9 cells at 1:1 ratio: (C) The mixed cells grew at an early state; (D) The mixed cells covered the entire culture plates. (E) The proliferation of A549 and PC9 cells at 0:1, 1:1 and 1:0 ratios for 7 days. Results are shown as the mean \pm SD from three independent experiments. The significant differences between the groups were analyzed by analysis of variance, and $\mathrm{P}<0.05$ are considered significant.

gefitinib. However, as shown in Figs. 3 and 4, different from group $\mathrm{b} / \mathrm{g}$ and group a/f, the anti-proliferative effects of the group $\mathrm{c}$ and $\mathrm{h}$ regimens were simply a sum of EGFR-TKI and chemotherapy therapy without any synergistic or antagonistic effect. Due to the withdrawal of gefitinib after $24 \mathrm{~h}$, the cells reentered into the cell cycle from G1 phase arrest and their sensitivity to paclitaxel/gemcitabine was restored. Therefore, the therapeutic effect of group $\mathrm{c} / \mathrm{h}$ was in the middle of the nine schedules.

TKI treatment is preferred in advanced lung cancer harboring EGFR-sensitive mutation, but the heterogeneity of lung cancer is a key limitation of single TKI treatment. Based on previous study, it is of vital importance to obtain the EGFR mutation status at the initial diagnosis of advanced NSCLC disease to optimize the therapeutic approach; nonetheless, an advantage was still observed in that gemcitabine/paclitaxel followed by gefitinib appeared favorable as compared to other schedules when A549 cells were mixed with PC9 cells at a 1:0 ratio. This is the first experiment in vitro to model tumor heterogeneity in the human microenvironment. Yang et al (24) demonstrated that paclitaxel-carboplatin combined with intercalated gefitinib showed a high response rate when the EGFR mutation status was unknown Kim et al (25) and Jakobsen and Sorensen (26) believed that the heterogeneity of NSCLC, and chemotherapy-induced changes in biomarker expression modifying the sensitivity of NSCLC to EGFR-TKI activity, may be a potential hypothesis as to why EGFR-TKIs show efficacy also in EFGR wild-type patients. 
On the other hand, Kubo et al (21) found that a regimen of carboplatin and paclitaxel followed by gefitinib, compared with the reverse sequence, in patients with advanced NSCLC was not favorable, regardless of their EGFR mutation status. Although TKI has been regarded as the standard first-line treatment in patients with advanced lung cancer, due to intratumor and intertumor heterogeneity under a different selection (27), there are some limitations when TKI is used as a single therapy, or is combined with chemotherapy or other therapy. According to this study, the anti-proliferative effects of six different sequence regimens were not affected by tumor heterogeneity. This may be related to the fact that the A549 and PC9 cells we selected did not accurately mimic the human tumor microenvironment. We also did not co-culture other cell lines. In this regard, it still remains an open question. In addition, some research found that EGFR-TKI plus chemotherapy could not only improve the antitumor effect, but could also delay and prevent the appearance of gefitinib-resistance clones $(28,29)$. This therapy may overcome the heterogeneity in the resistance to gefitinib (30).

In conclusion, the present study demonstrated that the most efficacious schedule to treat NSCLC in vitro was the sequence of gemcitabine/paclitaxel followed by getifinib, which was unaffected by tumor heterogeneity. We also characterized the molecular mechanisms involved in the synergistic effect between gemcitabine/paclitaxel and getifinib against the NSCLC cell lines. The experimental results have been confirmed by clinical data, and they could provide a potential treatment option in patients with advanced NSCLC and for the ongoing clinical investigation of the sequential treatment of NSCLC.

\section{Acknowledgements}

Not applicable.

\section{Funding}

The present study was funded by the Wu Jieping Medical Fund, which has no grant number.

\section{Availability of data and materials}

The datasets used during the present study are available from the corresponding author upon reasonable request.

\section{Authors' contributions}

XW and LZ conceived and designed the study. YQ, KX, SQ and $\mathrm{PZ}$ performed the experiments. $\mathrm{XW}$ and $\mathrm{LZ}$ wrote the manuscript. LZ, YQ and KX reviewed and edited the manuscript. All authors read and approved the manuscript and agree to be accountable for all aspects of the research in ensuring that the accuracy or integrity of any part of the work are appropriately investigated and resolved.

\section{Ethics approval and consent to participate}

This study does not contain any experiments with human tissues or animals.

\section{Patient consent for publication}

Not applicable.

\section{Competing interests}

The authors state that they have no competing interests.

\section{References}

1. Pignata M, Chouaid C, Le Lay K, Luciani L, McConnachie C Gordon $J$ and Roze S: Evaluating the cost-effectiveness of afatinib after platinum-based therapy for the treatment of squamous non-small-cell lung cancer in France. Clinicoecon Outcomes Res 9: 655-668, 2017.

2. Novello S, Barlesi F, Califano R, Cufer T, Ekman S, Levra MG Kerr K, Popat S, Reck M, Senan S, et al: Metastatic non-small-cell lung cancer: ESMO Clinical Practice Guidelines for diagnosis, treatment and follow-up. Ann Oncol 27 (Suppl 5): V1-V27, 2016.

3. Wu YL, Saijo N, Thongprasert S, Yang JC, Han B, Margono B, Chewaskulyong B, Sunpaweravong P, Ohe Y, Ichinose Y, et al: Efficacy according to blind independent central review: Post-hoc analyses from the phase III, randomized, multicenter, IPASS study of first-line gefitinib versus carboplatin/paclitaxel in Asian patients with EGFR mutation-positive advanced NSCLC. Lung Cancer 104: 119-125, 2017.

4. Patil VM, Noronha V, Joshi A, Choughule AB, Bhattacharjee A, Kumar R, Goud S, More S, Ramaswamy A, Karpe A, et al: phase III study of gefitinib or pemetrexed with carboplatin in EGFR-mutated advanced lung adenocarcinoma. ESMO Open 2: e000168, 2017.

5. Batson S, Mitchell SA, Windisch R, Damonte E, Munk VC and Reguart N: Tyrosine kinase inhibitor combination therapy in first-line treatment of non-small-cell lung cancer: Systematic review and network meta-analysis. Onco Targets Ther 10: 2473-2482, 2017

6. Skrzypski M, Szymanowska-Narloch A and Dziadziuszko R: Osimertinib-Effective treatment of NSCLC with activating EGFR mutations after progression on EGFR tyrosine kinase inhibitors. Contemp Oncol 21: 254-258, 2017.

7. Chen YM, Liu JM, Chou TY, Perng RP, Tsai CM and Whang-Peng J: phase II randomized study of daily gefitinib treatment alone or with vinorelbine every 2 weeks in patients with adenocarcinoma of the lung who failed at least 2 regimens of chemotherapy. Cancer 109: 1821-1828, 2007.

8. Cheng Y, Murakami H, Yang PC, He J, Nakagawa K, Kang JH, Kim JH, Wang X, Enatsu S, Puri T, et al: Randomized phase II trial of gefitinib with and without pemetrexed as first-line therapy in patients with advanced nonsquamous non-small-cell lung cancer with activating epidermal growth factor receptor mutations. J Clin Oncol 34: 3258-3266, 2016.

9. Soria JC, Wu YL, Nakagawa K, Kim SW, Yang JJ, Ahn MJ, Wang J, Yang JC, Lu Y, Atagi S, et al: Gefitinib plus chemotherapy versus placebo plus chemotherapy in EGFR-mutation-positive non-small-cell lung cancer after progression on first-line gefitinib (IMPRESS): A phase 3 randomised trial. Lancet Oncol 16: 990-998, 2015.

10. Jian H, Li W, Ma Z, Huang J, Feng J, Song Y, Gao B, Zhu H, Tao M, Bai C, et al: Intercalating and maintenance gefitinib plus chemotherapy versus chemotherapy alone in selected advanced non-small cell lung cancer with unknown EGFR status. Sci Rep 7: 8483, 2017.

11. La Salvia A, Rossi A, Galetta D, Gobbini E, De Luca E, Novello S and Di Maio M: Intercalated chemotherapy and epidermal growth factor receptor inhibitors for patients with advanced non-small-cell lung cancer: A systematic review and meta-analysis. Clin Lung Cancer 18: 23-33, 2017.

12. Qiao L, Wang J, Long G and Jiang Y: Sequential treatment of tyrosine kinase inhibitor and platinum-based doublet chemotherapy on EGFR mutant non-small cell lung cancer: A meta-analysis of randomized controlled clinical trials. Onco Targets Ther 10: 1279-1284, 2017

13. Zhao S, Gao F, Zhang Y, Zhang Z and Zhang L: Bevacizumab in combination with different platinum-based doublets in the first-line treatment for advanced nonsquamous non-small-cell lung cancer: A network meta-analysis. Int J Cancer 142: 1676-1688, 2018 
14. Li J, Wang S, Su ZF and Yuan Y: Synergistic effects of sorafenib in combination with gemcitabine or pemetrexed in lung cancer cell lines with K-ras mutations. Contemp Oncol 20: 33-38, 2016

15. Wang MC, Liang X, Liu ZY, Cui J, Liu Y, Jing L, Jiang LL, Ma JQ Han LL, Guo QQ, et al: In vitro synergistic antitumor efficacy of sequentially combined chemotherapy/icotinib in nonsmall cell lung cancer cell lines. Oncol Rep 33: 239-249, 2015.

16. Mok TS, Wu YL, Yu CJ, Zhou C, Chen YM, Zhang L, Ignacio J, Liao M, Srimuninnimit V, Boyer MJ, et al: Randomized, placebo-controlled, phase II study of sequential erlotinib and chemotherapy as first-line treatment for advanced non-small-cell lung cancer. J Clin Oncol 27: 5080-5087, 2009.

17. Wu YL, Lee JS, Thongprasert S, Yu CJ, Zhang L, Ladrera G, Srimuninnimit V, Sriuranpong V, Sandoval-Tan J, Zhu Y et al: Intercalated combination of chemotherapy and erlotinib for patients with advanced stage non-small-cell lung cancer (FASTACT-2): A randomised, double-blind trial. Lancet Oncol 14: 777-786, 2013.

18. Han B, Jin B, Chu T, Niu Y, Dong Y, Xu J, Gu A, Zhong H, Wang H, Zhang X, et al: Combination of chemotherapy and gefitinib as first-line treatment for patients with advanced lung adenocarcinoma and sensitive EGFR mutations: A randomized controlled trial. Int J Cancer 141: 1249-1256, 2017.

19. Yoshimura N, Kudoh S, Mitsuoka S, Yoshimoto N, Oka T, Nakai T, Suzumira T, Matusura K, Tochino Y, Asai K, et al: Phase II study of a combination regimen of gefitinib and pemetrexed as first-line treatment in patients with advanced non-smal cell lung cancer harboring a sensitive EGFR mutation. Lung cancer 90: 65-70, 2015.

20. Gridelli C, Ciardiello F, Gallo C, Feld R, Butts C, Gebbia V, Maione P, Morgillo F, Genestreti G, Favaretto A, et al: First-line erlotinib followed by second-line cisplatin-gemcitabine chemotherapy in advanced non-small-cell lung cancer: The TORCH randomized trial. J Clin Oncol 30: 3002-3011, 2012.

21. Kubo E, Yamamoto N, Nokihara H, Fujiwara Y, Horinouchi H, Kanda S, Goto Y and Ohe Y: Randomized phase II study of sequential carboplatin plus paclitaxel and gefitinib in chemotherapy-naïve patients with advanced or metastatic non-small-cell lung cancer: Long-term follow-up results. Mol Clin Oncol 6: 56-62, 2017.

22. Wu M, Yuan Y, Pan YY and Zhang Y: Combined gefitinib and pemetrexed overcome the acquired resistance to epidermal growth factor receptor tyrosine kinase inhibitors in non-small cell lung cancer. Mol Med Rep 10: 931-938, 2014.
23. Wu M, Yuan Y, Pan YY and Zhang Y: Antitumor activity of combination treatment with gefitinib and docetaxel in EGFR-TKI-sensitive, primary resistant and acquired resistant human non-small cell lung cancer cells. Mol Med Rep 9: 2417-2422, 2014

24. Yang J, Shi Y, Zhang X, Xu J, Wang B, Hao X, Li J and Yan W: Phase II trial of paclitaxel-carboplatin with intercalated gefitinib for untreated, epidermal growth factor receptor gene mutation status unknown non-small cell lung cancer. Thorac cancer 5: 149-154, 2014.

25. Kim EY, Cho EN, Park HS, Kim A, Hong JY, Lim S, Youn JP, Hwang SY and Chang YS: Genetic heterogeneity of actionable genes between primary and metastatic tumor in lung adenocarcinoma. BMC Cancer 16: 27, 2016.

26. Jakobsen JN and Sorensen JB: Intratumor heterogeneity and chemotherapy-induced changes in EGFR status in non-small cell lung cancer. Cancer Chemother Pharmacol 69: 289-299, 2012.

27. de Biase D, Genestreti G, Visani M, Acquaviva G, DiBattista M, Cavallo G, Paccapelo A, Cancellieri A, Trisolini R, Degli Esposti R, et al: The percentage of epidermal growth factor receptor (EGFR)-mutated neoplastic cells correlates to response to tyrosine kinase inhibitors in lung adenocarcinoma. PLoS One 12: e0177822, 2017.

28. Yoon S, Lee DH and Kim SW: Gefitinib with pemetrexed as first-line therapy in patients with advanced nonsquamous non-small cell lung cancer with activating epidermal growth factor receptor mutations. Ann Transl Med 5: 11, 2017.

29. La Monica S, Madeddu D, Tiseo M, Vivo V, Galetti M, Cretella D, Bonelli M, Fumarola C, Cavazzoni A, Falco A, et al: Combination of gefitinib and pemetrexed prevents the acquisition of TKI resistance in NSCLC cell lines carrying EGFR-activating mutation. J Thorac Oncol 11: 1051-1063, 2016.

30. Xu CR, Zhong WZ, Zhou Q, Zhang XC, Yang JJ and Wu YL: Heterogeneity of the resistance to gefitinib treatment in a non-small cell lung cancer patient with active epidermal growth factor receptor mutation. Thorac Cancer 8: 51-53, 2017. 